\title{
O Direito Penal da Prevenção como resposta ao Populismo Penal: As emoções públicas como dimensões menosprezadas da Políitica Criminal
}

\section{RUI CARIA}

\begin{abstract}
The rise of penal populism has become alarming due to the increase of its supporters and the growing severity of the punishments it demands to turn into law. It takes advantage of political emotions to achieve its goals, channeling fear and anger into proposals for legislations. Today's criminal policy is guided by the goal of crime prevention, finding strength in the principles of the Constitution and the Democratic State of Law. However, it does not seem to concern itself with public emotion. Giving up the task of channeling public emotion into public policy to populist actors can be regarded as a great danger to Democracy. Our study's aim is to reflect on the importance of

public emotion in a preventive criminal policy as an answer to penal populism. With this in mind, we shall analyze how each one of these frames treats public emotions, highlighting how preventive criminal policy can use positive emotions to strengthen its guiding principles and honor them through legislation. The topic of public emotions has been growing among development policy studies; however, it has not been fully developed in criminal law. In this way, we see our study as one of the first contributions to the development of this view. These can have an influence upon the way we construct penal-dogmatic categories such as guilt, as well as help humanize and individualize sentencing.
\end{abstract}

Keywords: Criminal Law; Criminal Policy; Populism; Public Emotions

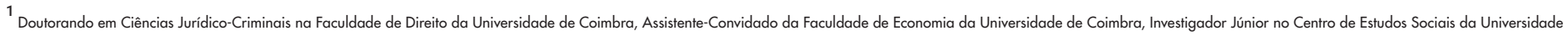
de Coimbra, Fellow da Sylff Association.
} 


\section{Introdução}

Foi divulgada recentemente ${ }^{2}$ a decisão do Tribunal da Comarca de Lisboa que condenou André Ventura e o partido Chega a pedir desculpas a uma família do Bairro da Jamaica a quem se referiram como "bandidos" ${ }^{\prime \prime}$. Na decisão, o Tribunal reconheceu "a ilicitude das ofensas ao direito à honra e ao direito à imagem", decorridas no âmbito do debate televisivo das eleições presidenciais de 2021. Durante o debate, o candidato exibiu uma fotografia do oponente Marcelo Rebelo de Sousa com uma família de sete pessoas desse bairro. Já o partido Chega, na sua conta do Twitter, aproveitou a mesma imagem para a opor a uma segunda imagem do candidato com outros homens, um deles com uma t-shirt do Movimento Zero, com a legenda "Eu prefiro os portugueses de bem".
Não nos surpreende o confronto que deu lugar a esta decisão do Tribunal. Apenas veio concretizar uma promessa que já estava implícita no discurso dos condenados. Durante a sua campanha como candidato à presidência da República, o candidato André Ventura proclamou-se $\bigcirc$ "Presidente dos portugueses de bem". Da afirmação deste slogan resultava uma dicotomia incompleta. Se existem portugueses de bem, quem são os outros? A pergunta ficou no ar, até ao momento do debate presidencial. Completou-se a dicotomia: há "portugueses de bem" e há os "bandidos".

\footnotetext{
2 Relativamente à data em que se escreve este artigo.

${ }^{3}$ Sobre a sentença e as afirmações nela contidas que se seguem:

htps://observador.pt/2021/05/24/andre-ventura-condenado-por-ter-chamado-bandidos-a-moradores-do-bairro-da-jamaica/ ; htpps://expresso.pt/politica/2021-05-24-Andre-Ventura-condenado-a-pedir-desculpa-a-familia-a-quem-chamou bandidos-ef2a8461; htps://www.ts.pt/portugal/politica/andre-ventura-condenado-por-ofender-familia-do-bairro-da-jamaica-13760553.html
} 
Também o Tribunal observou esta dicotomia, notando que as pessoas em causa "são apresentados como o oposto dos portugueses de bem, colados a um discurso em que se fala deles e das pessoas como eles de forma depreciativa". Acresce que se tratam de "pessoas moradoras de um bairro degradado e de modesta condição social, na sua maioria vindas de países Africanos, a cuja imagem o Réu cola toda uma panóplia de menções depreciativas".

Para nós, o conflito subjacente à decisão apresentada revela-se uma oportunidade didática, na medida em que se configura como um exemplo da forma como o populismo faz uso das emoções públicas para levar a cabo os seus objetivos políticos, nomeadamente, no âmbito da política criminal. É sabido que André Ventura e o Chega não se têm imiscuído de partilhar as suas ideias para propostas legislativas de natureza penal: a pena de prisão perpétua ${ }^{4}$, a pena de castração física ou química para agentes de crimes de abuso sexual de menores ${ }^{5}$, o aumento em dobro ${ }^{6}$ do limite máximo da moldura dos crimes de corrupção - entre outras. A força do discurso populista é alimentada pela dicotomia concretizada nos termos anteriormente descritos, mas que podem bem ser alternativamente concebida como uma cisão entre os "bons" e os "maus". Assim, de forma pouco sofisticada, mas prática, está assente a base sobre a qual se procurará construir um Direito Penal de Defesa Social ou um Direito Penal do Inimigo.
A revelação de que do outro lado dos "portugueses de bem" estão os "bandidos" soou como um alerta que nos urge a escrever em defesa do Estado de Direito Democrático, apresentando o direito penal da prevenção como resposta ao direito penal da defesa social e ao populismo penal em que este se alicerça. Para colocar em evidência a necessidade de reforçar o paradigma preventivo do direito penal, iremos começar o nosso estudo pelo papel das emoções públicas na política criminal. A partir delas conseguiremos compreender onde reside a força de uma política criminal que toma como seu fim a prevenção criminal, como esta está em linha com a axiologia constitucional e os modelos atuais de desenvolvimento dos Estados e, em última linha, com a compreensão da vulnerabilidade.

Através deste estudo, e das reflexões que o compõem, pretendemos oferecer um contributo para o desenvolvimento de respostas contra o populismo penal e reforçar a posição do Estado de Direito Democrático, bem como de um direito penal e política criminal construídos à imagem dos seus princípios.

\footnotetext{
4 https://www.publico.pt/2020/02/29/politica/noticia/ventura-vai-propor-prisao-perpetua-homicidas-pedofilos-1906006

5 https://www.publico.pt/2020/09/22/politica/noticia/revisao-constitucional-chega-preve-castracao-fisica-pedofilos-1932475

6 https://www.publico.pt/2020/09/22/politica/noticia/revisao-constitucional-chega-preve-castracao-fisica-pedofilos-1932475
} 


\section{Emoções públicas e políticas públicas}

MARTHA NUSSBAUM sustenta que todos os princípios políticos, bons e maus, precisam de suporte emocional para garantir a sua estabilidade ao longo do tempo, e todas as sociedades decentes precisam de ser cautelosas quanto à divisão e hierarquização cultivando sentimentos ${ }^{7}$ apropriados de simpatia e amor ${ }^{8}$. A Autora define duas tarefas de cultivo político das emoções para a criação de uma sociedade liberal justa e igualitária9 : em primeiro lugar, e por um lado, mobilizar o compromisso dos cidadãos com projetos dedicados ao bem comum; em segundo lugar, e por outro lado, controlar tendências de vitimização e de proteção da fragilidade através da discriminação e subordinação de outros ${ }^{10}$. A importância das emoções nas políticas públicas tem sido subestimada por várias razões. Em primeiro lugar, por ignorância quanto ao seu papel na tomada de decisões racionais. As emoções estão muitas vezes associadas na consciência popular à irracionalidade, sendo encaradas como obstáculos ao processo decisório guiado pela razão ${ }^{11}$. Na verdade, sucede exatamente o contrário. Como explica ANTÓNIO DAMÁSIO: "Em suma, sentir os estados emocionais, o que geralmente equivale a afirmar que se tem consciência das emoções, oferece-nos flexibilidade de resposta com base na história específica das nossas interações com 0 meio ambiente"12. Em segundo lugar, na observação pertinente de MARTHA NUSSBAUM, muitas vezes as pessoas supõem que só as sociedades fascistas ou agressivas é que são intensamente emocionais e, portanto, só estas têm que se preocupar com o papel das emoções nas políticas públicas - o que é uma crença errada e perigosa ${ }^{13}$. Com base nesta crença, a tarefa da canalização das emoções públicas é cedida exclusivamente a movimentos antidemocráticos, oferecendo-thes uma vantagem neste terreno que se revela prejudicial para a democracia. É notória a forma como movimentos populistas e de extremadireita fazem uso do medo e da raiva para impulsionar os seus discursos, reforçar os seus argumentos e, finalmente, conseguirem a aprovação das suas propostas. Da mesma forma que estes atores políticos canalizam emoções negativas para atingirem os seus objetivos antidemocráticos, exige-se movimentos políticos democráticos que canalizem emoções positivas no sentido de reforçar políticas públicas que garantam a justiça social, igualdade e desenvolvimento. Esta exigência vale para a política criminal, que terá que ser construída no sentido do reconhecimento das emoções como dimensão essencial da

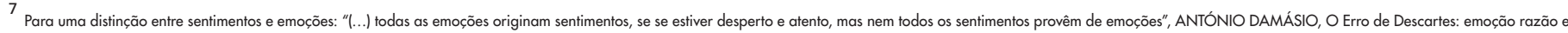
cérebro humano (Temas e debates, 2019), p. 194.

8 MARTHA NUSSBAUM, Political Emotions: Why love matters for justice (Belknap Press of Harvard University Press, 2015), p. 3.

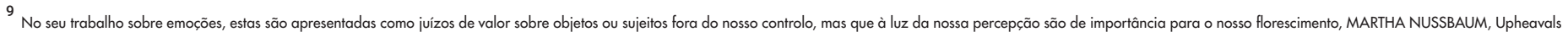

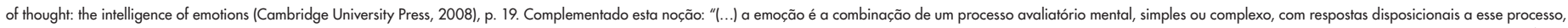

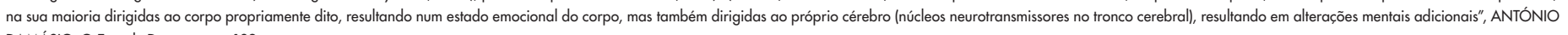
DAMÁSIO, O Erro de Descartes, p. 189.

10 MARTHA NUSSBAUM, Political Emotions, p. 3.

${ }^{11}$ Sobre esta perspectiva, "Assim, concebemos as emoções como uma faculdade mental extra, um acompanhante dispensável do nosso pensamento racional que a natureza nos impõe", ANTÓNIO DAMÁSIO, O Erro de Descartes, p. 85.

12 Idem, p. 182.

${ }^{13}$ MARTHA NUSSBAUM, Political Emotions, p. 2.
} 
pessoa e variável de referência nos seus processos decisórios. Mas as emoções não se revelam de importância apenas para a tomada de decisões racionais. Na sua compreensão e reconhecimento está implícita a compreensão de um aspeto indissociável da dignidade da pessoa humana: a vulnerabilidade (ou fragilidade ${ }^{14}$ ). Na medida em que as emoções são juízos de valor sobre objetos ou sujeitos fora do nosso controlo, mas de importância para o nosso florescimento, nelas se reconhece a nossa falta de autossuficiência, bem como o facto de o nosso desenvolvimento se encontrar dependente de fatores externos. As emoções, enquanto dimensões internas da pessoa, são também vulneráveis às circunstâncias, podendo o seu desenvolvimento ser afetado por elas ${ }^{15}$.

A ironia do populismo no âmbito da política criminal reside no facto de negar esta vulnerabilidade da pessoa ao mesmo tempo fazendo uso dela para conseguir os seus objetivos. Já a insuficiência da prevenção reside no facto de reconhecer a vulnerabilidade emocional da pessoa, na medida em que se alicerça sobre a dignidade da pessoa humana, mas não desenvolveu (ainda) um discurso coerente sobre como a abordar. Pelas razões já apontadas, é urgente o desenvolvimento desse discurso, devidamente sustentado nos princípios constitucionais que enformam a política criminal e apontado para a prevenção como fim.

\section{A dimensão emocional do populismo penal}

Para uma compreensão clara de como o populismo faz uso das emoções públicas na persecução dos seus objetivos há que começar por uma compreensão do que é o populismo. CRISTINA M. M. QUEIROZ procura uma definição através da comparação com a figura da demagogia ${ }^{16}$. Recorda $\circ$ demagogo na Grécia Antiga como "aquele que dirige o povo, o chefe, o líder, o condutor". Apesar de tanto a demagogia como o populismo se apresentarem como "formas degeneradas" da Democracia, a diferença reside no facto de este ocorrer num contexto democrático, apesar da sua subversão das instituições e práticas políticas ${ }^{17}$. Mesmo nestas condições, o populismo não nega a representação política, ao invés, insiste que "só eles" se apresentam como os "representantes legítimos do povo"18. Trata-se de um populismo excludente e autoritário que representa "o povo" em contraste com os "outros" que discordam com a opinião daqueles ${ }^{19}$.

Nesta caracterização facilmente encaixa a narrativa do "presidente dos portugueses de bem". Esses, sim, são o povo, e aquele, sim, é o seu representante. Excluídos ficam os outros, os "bandidos", que não merecem representação, pois não são sequer povo. Não sendo povo, não thes assistirão os mesmos direitos que são garantidos pelo Estado. Não são "de bem",

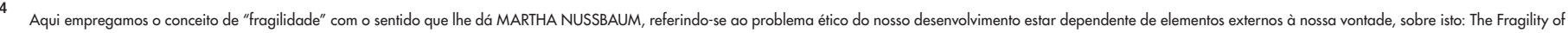
Goodness: luck and ethics in Greek tragedy and philosophy (Cambridge University Press), 2013.

15

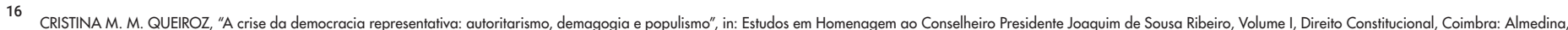
2019 , p. 591.

17 Idem, p. 592

18 Ibidem.

19 Neste sentido, STEPHEN WEBB, "Populism: A Threat to Democracy? Or a Verification of it?", in: Journal of Contextual Economics, 137, 2017, p. 403.
} 
pois vale invocar a observação de FRIEDRICH NIETZSCHE de que o "bem" é muitas vezes construído por aqueles que se entitulam de "bons": "(..) the aristocratic, the powerful, the highstationed, the high-minded, who have felt that they themselves were good, and that their actions were good, that is to say of the first order", contrapondo-se aos que consideram como "(...) low, the low-minded, the vulgar, and the plebeian ${ }^{\prime 20}$. Constróise uma perspectiva que nega a pluralidade, em favor de um maniqueísmo sem assento na realidade, incompatível com os princípios do Estado de Direito Democrático. Esta é a tela sobre a qual o populismo pinta uma visão dramática do mundo ${ }^{21}$ , distorcendo a perceção pública de determinados tópicos através do apelo a instintos e emoções negativas, ao mesmo tempo ignorando os factos que envolvem a sua realidade complexa. A visão dramática mostra um mundo inseguro, abundante em perigos e com potencial de nos magoar, onde o medo é um dever. HANS ROSLING alerta que o instinto do medo ${ }^{22}$ apela fortemente à visão dramática do mundo, impedindo-nos de pensar criticamente e ter uma visão do mundo baseada em factos ${ }^{23}$.

Pintado este quadro do mundo, o populismo ergue propostas à medida deste, com o propósito de oferecer a segurança que o medo exige. No que à política criminal diz respeito, o populismo guia-se pelo paradoxo da vulnerabilidade: por um lado, ao apelar a uma visão dramática do mundo, retrata os cidadãos como vulneráveis face à insegurança; por outro lado, ao retratar os agentes de crimes como ausentes de dignidade, ignora a vulnerabilidade destes em relação às circunstâncias que não thes permitiram viver a sua vida de forma responsável sem cometer crimes. Insistindo nestas conceções erradas e incompatíveis do mundo e da natureza humana, pedem um direito penal mais securitário e mais gravoso, "porque só os outros são criminosos" ${ }^{124}$.

O populismo idealiza a vontade do povo (também ele idealizado), interpretando-a à luz da sua visão do mundo e da pessoa, muitas vezes atacando as instituições políticas e legais já existentes, julgando-as inadequadas ${ }^{25}$. Na síntese de GERMANO MARQUES DA SILVA: "Nada mais é preciso aos políiticos para, farejando a emoção popular e o seu medo pela insegurança real ou induzida, ajustar as respostas legislativas. populismo penal de certas ideologias aproveita do medo e reflexo punitivo dos cidadãos para recolher apoios favoráveis à lei e à ordem $(. . .)^{\prime \prime 26}$.

O populismo penal, no que diz respeito à forma como opera sobre a política criminal, leva à "adoção de leis repressivas, tanto de natureza substantiva como adjetiva, sustentadas em finalidades políticas e eleitorais, com o objetivo de aumentar o capital político de quem as aprova, sem levar em consideração a eficácia e os efeitos das mesmas, mas, sobretudo, sustentadas numa mediatização dos fenómenos judiciais ${ }^{2127}$.

À dimensão emocional do medo em que se apoia o populismo, acresce a canalização que faz da raiva. A raiva é uma emoção complexa. $\bigcirc$ seu conteúdo cognitivo engloba um desejo acompanhado de dor por uma retribuição imaginada devido a uma ofensa imaginada infligida por alguém que não tem razão legítima para infligir a ofensa nessa pessoa ${ }^{28}$.

\footnotetext{
20 FRIEDRICH NIETZSCHE, The Genealogy of Morals (Dover Publications, 2018), p. 11.

21 Sobre a visão dramática do mundo e a visão do mundo baseada em factos: HANS ROSLING, OLA ROSLING, ANNA ROSLING RONNLUND, Factfulness (Sceptre, 2019), p.13 e ss.

22 Aqui referimo-nos ao medo enquanto instinto, sublinhando a maneira como este afeta a perceção, sem prejuízo de em outros momentos do estudo o tratarmos enquanto emoção e a forma como este afeta o comportamento.

23 HANS ROSLING, OLA ROSLING, ANNA ROSLING RONNLUND, Factfulness, p. 101 ess

24 GERMANO MARQUES DA SIIVA, "Populismo e Direito Penal - A Crise Permanente", in: Revista do CEJ, I, 2014, p. 324

25 STEPHEN WEBB, "Populism: A Threat to Democracy? Or a Verification of it?", in: Journal of Contextual Economics, 137, 2017, p. 404.

26 Germano maRQues dA SILVA, "Populismo e Direito Penal - A Crise Permanente", in: Revista do CEJ, I, 2014, p. 328.
} 
- desejo de retribuição é traduzido normativamente nas propostas de agravamento da severidade da punição que são frequentemente lançadas sob a narrativa do populismo penal. Sendo que esta retribuição é um elemento conceptual da raiva ${ }^{29}$, as exigências constantes de retribuição por parte do populismo penal são um exemplo de canalização da raiva como emoção pública através da política criminal.

As considerações antecedentes trazem o populismo penal ao encontro das teorias retributivas que concetualizam a pena como o "justo equivalente" do dano do facto e da culpa do agente $^{30}$, incompatíveis, em diversos níveis com os princípios que legitimam a intervenção punitiva do Estado ${ }^{31}$. Apesar de normativamente o direito penal consagrar as finalidades das penas como essencialmente preventivas, a discussão doutrinal mantém-se empenhada. Autores contemporâneos, como FARIA COSTA, não deixam de afirmar, convictamente: "Pensamos, fundadamente, que a pena tem um sentido e uma finalidade ético-jurídicos essencialmente retributivos ${ }^{132}$.

\section{A dimensão emocional da política criminal preventiva}

A prevenção criminal remonta ao pensamento de CESARE BECCARIA, que apontou como finalidade de toda a boa legislação, mais do que castigar crimes, preveni-los ${ }^{33}$. Ao seu tempo, já considerava que a prevenção criminal estava dependente de fatores externos ao comportamento criminal, os quais deveriam por ela ser tidos em conta, na medida em que deles estava dependente o seu sucesso ${ }^{34}$. É reconhecido no seu discurso que a vontade humana é fortemente influenciada por estímulos externos ${ }^{35}$. Desta forma, o primeiro teórico dedicado à prevenção criminal sabia que esta não podia ignorar a vulnerabilidade (ou fragilidade) humana face a condições externas fora do seu controlo.

Atualmente, a prevenção apresenta-se como fim do direito penal, conferindo-the pragmaticidade e sentido útil quanto a si e aos seus efeitos, sendo comparável a uma "espiritualidade" que o habita e orienta ${ }^{36}$. $O$ próprio Código Penal é explicito quanto a este entendimento, consagrando no seu artigo 40. como finalidades das penas, não só a proteção de bens jurídicos, mas também a reintegração do agente na sociedade. Destas finalidades é possível derivar a natureza de ultima ratio que assume a intervenção do poder punitivo do Estado, subjugado ao principio da proporcionalidade assente no artigo 18. , n. ${ }^{\circ}$ 2, da Constituição da República Portuguesa. Na formulação de MANUEL DA COSTA ANDRADE: $\bigcirc$ direito penal só está, noutros termos, legitimado a servir valores ou metas imanentes ao sistema social e não fins transcendentes de índole religiosa, metafísica, moralista ou ideológica ${ }^{37}$.

\footnotetext{
27 JOSÉ MOURAZ LOPES, "Fragilidades do discurso criminalizador na corrupção: entre o populismo e a ineficácia", in: Julgar, n. . 32, 2017, p. 127.

28 MARTHA NUSSBAUM, Anger and Forgiveness: resentment, generosity, justice (New York: Oxford University Press, 2019 ), p. 17.

29 Neste sentido, Idem, p. 15.

30

31

Sobre estas incompatibilidades, Ibidem.

32 FARIA COSTA, O Perigo em Direito Penal (Coimbra: Coimbra Editora, 2000), p. 373

33 CESARE BECCARIA, On Crimes and Punishments (Blackmask Online, Ebook, 2001), p. 9

34 Neste sentido, URS KINDHAUSER, "Acerca de la concepción de la prevención criminal de Cesare Beccaria", in: Revista Brasileira de Ciências Criminais, Ano 18, n. 87 , nov.-dez., 2010, p. 157.

35 Idem, p. 159.
} 
A caracterização preventiva das finalidades das penas acolhe também a ideia de vulnerabilidade. Os bens jurídicos correspondem a todas as condições e finalidades necessárias ao livre desenvolvimento do indivíduo, à realização dos seus direitos fundamentais e ao funcionamento de um sistema estatal construído em torno dessa finalidade ${ }^{38}$. Nesta ideia está implícito o reconhecimento de que o desenvolvimento do indivíduo está dependente de condições externas que estão fora do seu controlo. $O$ que vai ao encontro do ideal de ressocialização, bem como do pensamento de CESARE BECCARIA. A pena privativa da liberdade, assumindo-se como ultima ratio da política criminal, terá que se construir de forma a minimizar o seu efeito negativo e criminógeno ao mesmo tempo que se the promove um sentido positivo, prospetivo e socializador ${ }^{39}$.

Esta é, aliás, uma exigência decorrente do princípio da socialidade, que se constitui como princípio orientador do programa políitico-criminal, impondo ao Estado um dever de ajuda e solidariedade para com o condenado, proporcionandothe as condições necessárias para a sua reintegração na sociedade - artigo 9. ${ }^{\circ}$ al. d), da CRP, em que se estabelece como tarefa fundamental do Estado "promover o bem-estar e a qualidade de vida do povo", artigo 26. ${ }^{\circ},{ }^{\circ} .^{1}$, da CRP, na parte em que prevê o direito ao desenvolvimento da personalidade, e o artigo 30. ${ }^{\circ}$ n. ${ }^{\circ}$ 1, da CRP que proíbe penas e medidas de segurança privativas ou restritivas da liberdade com carácter perpétuo ${ }^{40}$.

Com este modelo de direito penal liberal assente na proteção de bens jurídicos, conflituam outros modelos, como sejam o do moralismo jurídico-penal, as teses do direito penal ${ }^{41}$ da segurança ${ }^{42}$, ou os discursos do direito penal do inimigo ${ }^{43}$. Todos eles podem, em vertentes variadas, ser ligados ao populismo penal.

No que diz respeito à sua dimensão emocional, a políitica criminal preventiva, em contraposição ao populismo penal, apresenta uma estrutura que permite a canalização de emoções positivas. Da axiologia constitucional que enforma o nosso ordenamento jurídico-penal, oferecendo-the a sua racionalidade, reconhecemos como emoção prevalente a compaixão.

A compaixão é uma emoção dolorosa ocasionada pela consciência do infortúnio não merecido de outra pessoa ${ }^{44}$. É composta por três elementos cognitivos: a crença ou avaliação do sofrimento da outra pessoa como sendo sério e não trivial; a crença de que a pessoa não merece o sofrimento; a crença de que a pessoa que sente compaixão tem a mesmas possibilidades de sofrer que a pessoa cujo sofrimento testemunha ${ }^{45}$.

A partir da compaixão e do seu conteúdo cognitivo é possível elaborar um esboço da dimensão emocional da política criminal, ao mesmo tempo que se evidencia a incompatibilidade do

\footnotetext{
36 ANABELA MIRANDA RODRIGUES, A Determinação da Medida da Pena Privativa de Liberdade: os critérios da culpa e da prevenção (Coimbra: Coimbra Editora, 2014$),$ p. 307.

37 MANUEL DA COSTA ANDRADE, "A «Dignidade Penal» e a «Carência de Tutela Penal» como Referências de uma Doutrina Teleológico-Racional do Crime", Revista Portuguesa de Ciência Criminal, Ano 2, Fascículo 2, 1992, p. 178.

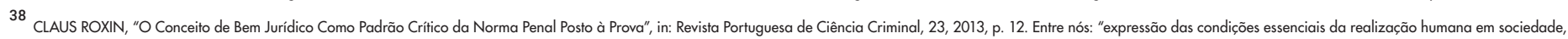

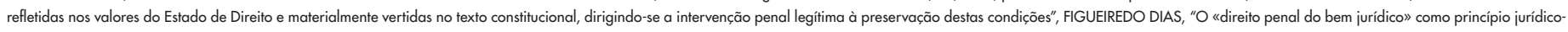

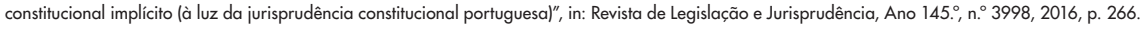

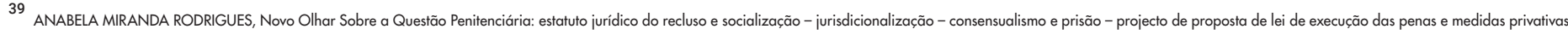
de liberdade" (Coimbra: Coimbra Editora, 2002), p. 31.

${ }^{40}$ Neste sentido, MARIA JOÃO ANTUNES, Penas e Medidas de Segurança (Coimbra: Almedina, 2018), p. 15.

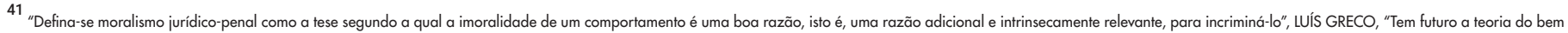
jurídico? Reflexões a partir da decisão do Tribunal Constitucional Alemão a respeito do crime de investo (§ 173 Strafgesetzbuch)", in: Revista Brasileira de Ciência Criminal, 82, 2010, p. 172.

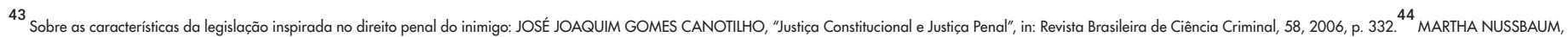
Upheavals of thought: the intelligence of emotions (Cambridge University Press, 2008), p. 301.

$45_{\text {Idem, p. } 306}$
} 
populismo com os princípios do Estado de Direito Democrático. Como já se colocou em evidência, o princípio da socialidade, enquanto princípio orientador da política criminal, assume-se como uma manifestação de compaixão por parte desta, na medida em que traduz normativamente o conteúdo cognitivo dessa emoção. Vejamos como se traduz cada um dos elementos: o reconhecimento do condenado a pena de prisão como alguém especialmente vulnerável denota a crença de que o seu sofrimento é sério - assim como a necessidade de evitar a prisão tendo em conta os seus efeitos criminógenos; reconhecendo a necessidade de o auxiliar denota a crença de que a pessoa não merece esse sofrimento; por fim, ao se admitir a possibilidade de ressocialização, admite-se que esta pessoa partilha da nossa vulnerabilidade e que, nessa medida, sendo dotado da mesma dignidade que nós, detém a razão e a capacidade de mudança necessárias para levar a sua vida de forma responsável.

A dignidade da pessoa humana, na qual assentamos o nosso Estado de Direito Democrático, e da qual derivam todas as nossas garantias constitucionais, assume-se como condição necessária para a canalização da compaixão na política criminal. Parte indissociável dessa mesma dignidade é, precisamente, a vulnerabilidade do nosso desenvolvimento a condições externas que estão fora do nosso controlo. O reconhecimento desta dimensão da natureza humana é imprescindível para que a política criminal canalize a compaixão, garantindo a longevidade dos seus princípios, ao mesmo tempo que contribui para a concretização dos seus objetivos.

A visão dramática do mundo que guia o populismo penal é terreno infértil para o desenvolvimento da compaixão nas políticas públicas. A cisão que faz entre os "bons" e os "outros" impossibilita a formação do conteúdo cognitivo necessário à existência da emoção em causa. No que diz respeito ao primeiro elemento, o populismo considera que o sofrimento dos condenados a pena de prisão é sério, tanto assim é que querem fazer uso da prisão como instrumento para thes causar mais sofrimento, prolongando os seus limites. Os impedimentos começam a surgir a partir do segundo e terceiro elemento. Quanto ao segundo elemento, as exigências punitivas que clama a narrativa populista não vão no sentido de admitir que o agente, em certa medida, pode não ter culpa das circunstâncias que o levaram a praticar determinado tipo de crime mas, pelo contrário, tomam essa culpa como total e fundamento de uma punição severa ${ }^{46}$. Por último, ressalta da dicotomia que impõe segundo a sua visão dramática do mundo que o populismo não considera que os agentes da prática de crimes partilham da dignidade que cabe às "pessoas de bem" e, nesta medida, sofrem porque são diferentes - "bandidos" -, não porque são vulneráveis às mesmas circunstâncias que podem levar a que a vida de qualquer um culmine na delinquência.

46 "Insofar as we believe that a person has come to grief through his or her own fault, we will blame and reproach, rather than having compassion", Idem, p. 311. 
A política criminal preventiva, por outro lado, através dos seus princípios orientadores guia-se por uma visão do mundo em que nem sempre as circunstâncias estão dentro do controlo da pessoa, podendo o seu desenvolvimento ser afetado pela tragédia. É o reconhecimento desta vulnerabilidade por parte da política criminal que the permite traduzir a compaixão pelos agentes de crimes em concretizações normativas, como as acima apontadas.

$\bigcirc$ princípio da socialidade e as finalidades preventivas especiais da pena impedem também a canalização da raiva através da política criminal. $\bigcirc$ ideal de ressocialização favorece a transição de raiva para um olhar positivo sobre - futuro, colocando travão nas consequências retributivas exigidas pelo conteúdo cognitivo daquela emoção. Assim:

"(...) the merciful judge looks backward. But at the same time, while acknowledging the fact of wrongdoing, and thus expressing society's commitment to core values, the judge also looks forward to a world of reintegration" 47.

\section{Conclusões}

Como observa MARTHA NUSSBAUM no seu estudo sobre emoções: "All emotions are note qual" ${ }^{48}$. Desta observação devemos retirar um sentido de cautela em relação ao papel das emoções públicas e a sua influência nas políticas públicas, com especial atenção à forma como certos atores políiticos podem fazer uso daquelas para erodir princípios cuja consagração nos foi tão cara e que sustentam o nosso progresso.

populismo penal propaga uma visão dramática do mundo, cultivando emoções negativas, como o medo e a raiva, para, sucessivamente, canalizar estas emoções no sentido da aprovação de propostas legislativas construídas à luz dessa perceção distorcida. Faz apelo aos instintos e não aos factos. As suas metas político-criminais são limitadas por uma visão de curto prazo, para responder imediatamente às "ameaças" à segurança. São traduções normativas de comportamentos motivados por emoções negativas, na medida em que também estas se preocupam com a resolução de problemas imediatos. Não só são as propostas legislativas do populismo penal incompatíveis com o direito penal de um Estado de Direito Democrático, como o é a sua visão. Ao se apoiarem em emoções negativas, os princípios de uma politica-criminal populista, mesmo a ser concretizados, estariam fadados à insustentabilidade ao longo do tempo.

Como bem sintetizou o Tribunal da Comarca de Lisboa na sua decisão: "Sabendo-se que todas as pessoas humanas partilham a mesma humanidade, que cada uma dessas pessoas tem em si mesma a capacidade para o bem e para o mal, devendo a censura social ser dirigida aos atos praticados e não às pessoas, esta diferenciação redutora entre bons e maus, entre pessoas de bem e bandidos, não reflete a natureza humana, nem pacifica as comunidades humanas". Bem esteve

\footnotetext{
47 MARTHA NUSSBAUM, Anger and Forgiveness: resentment, generosity, justice, p. 207.

48 MARTHA NUSSBAUM, Upheavals of thought: the intelligence of emotions (Cambridge University Press, 2008), p. 301.
} 
a jurisprudência em reconhecer que a natureza humana é frágil e, nessa medida, vulnerável a desenvolver-se de uma forma que culminará no crime.

Uma políica criminal preventiva assenta numa visão baseada em factos sobre a natureza humana e o estado atual da sociedade global, tendo potencial para cultivar compaixão e outras emoções positivas que vão no sentido da realização da justiça e do desenvolvimento global, sustentando os princípios que para tal contribuem. Faz apelo aos factos sobre quem somos e como o mundo é, não promovendo visões distorcidas sobre estas realidades. As metas político-criminais preventivas são apontadas para resultados a longo prazo, respondendo aos desafios de uma sociedade liberal em que o crime é uma realidade constante e em permanente transformação.

Como começámos por antecipar, apesar de a estrutura da política criminal preventiva e do Estado de Direito Democrático serem favoráveis à canalização da compaixão, ainda nos sobram algumas dúvidas quanto à forma como esta é concretizada a nível da dogmática jurídico-penal. No que diz respeito à teoria dos fins das penas, como já se demonstrou, a prevenção é o fim que orienta as consequências jurídicas do crime. A natureza de ultima ratio que reveste a intervenção punitiva do Estado abre lugar a soluções de diversão, garantias processuais dos arguidos e orientações ao nível da execução de penas que se podem identificar como traduções normativas da compaixão. Ao olharmos para o conteúdo material da culpa jurídico-penal é possível questionar até que ponto é que esta reconhece a fragilidade do bem e da capacidade de não praticar crimes. FIGUEIREDO DIAS refere que a culpa jurídico-penal realizada materialmente será o ter que responder pela personalidade éticosocialmente censurável que fundamenta um facto ilícito-típico ${ }^{49}$. Aliado a este conteúdo material está a culpa da atitude interior, na medida em que a expressão da personalidade do agente no facto se mostra uma atitude de contrariedade ou de indiferença, ou de descuido, ou de leviandade, perante a violação do bem jurídico protegido ${ }^{50}$. Esta personalidade, sob a qual assenta o juízo de culpa jurídico-penal, é uma personalidade ética do homem, referida à manifestação do seu ser em factos que violem o dever de realização e desenvolvimento do serlivre ${ }^{51}$. Neste entendimento observamos os conceitos de liberdade, personalidade e desenvolvimento, mas persistem as nossas dúvidas quanto à relação entre estes elementos, o seu conteúdo, e se este está alinhado de forma a reconhecer que o desenvolvimento da personalidade do agente é limitado por circunstâncias das quais este não tem controlo, pelo que a sua liberdade não é tão total quanto se possa conceber.

Ao se conceber um conteúdo material diferente da culpa jurídico-penal, ou mesmo alterando a conceção presente, as implicações far-se-iam sentir ao nível da determinação da pena privativa de liberdade. A "culpa para efeitos de medida da pena" poderá conceber-se à luz de várias teorias, algumas delas que dizem respeito ao desenvolvimento da personalidade ${ }^{52}$. Apesar das reconhecidas dificuldades, o avanço dos estudos sobre o desenvolvimento da personalidade,

\footnotetext{
49 FIGUEIREDO DIAS, Liberdade, culpa, direito penal (Coimbra: Coimbra Editora, 1995), p. 165.

50 Idem, p. 287.

51 Idem, p. 167.

52 Sobre isto, ANABELA MIRANDA RODRIGUES, "O Modelo de Prevenção na Determinação da Medida Concreta da Pena", in: Revista Portuguesa de Ciência Criminal, Ano 12, n.. 2, Abril-Junho, 2002 , p. 161.
} 
a sua dependência de fatores externos e, em última linha, a sua relação com a delinquência, pode constituir um novo suporte para o melhoramento do conteúdo material da culpa jurídicopenal de modo a torná-la mais individualizada e apta a uma determinação mais justa da medida da pena.

É de questionar, também em face da compreensão mais aprofundada da dependência do desenvolvimento da personalidade de fatores externos, se a posição e relação entre prevenção geral e especial se devem manter ao nível da determinação da pena. Segundo o modelo atual, a prevenção geral serve, no fundo, para limitar as considerações de prevenção especial quando estas fazem descer a pena abaixo do mínimo da culpa ${ }^{53}$. Contudo, cremos ser possível, neste momento, considerar a prevenção especial como um critério mais seguro de orientação da medida da pena do que a prevenção geral. $\bigcirc$ que nos leva a questionar se aquela não deverá assumir um lugar de prevalência em relação a esta num novo modelo de determinação da medida da pena.

Cumpre deixar claro que apesar de neste estudo apresentarmos o direito penal da prevenção como uma resposta ao populismo penal, não caímos na ingenuidade de considerar a prevenção, enquanto fim do direito penal, como uma solução imaculada e invulnerável a críticas. À luz do que tem vindo a ser dito ao longo deste estudo, o facto de a prevenção geral se basear nas expectativas da comunidade deixa-a especialmente vulnerável à influência do populismo penal. Já se viu o quanto distorcidas podem ser as expectativas da comunidade e os instrumentos que neste momento abundam para a tornar assim. Não queremos com isto dizer que a prevenção especial é livre de críticas ou incompletudes, mas mostra-se mais protegida da influência do populismo na medida em que se baseia numa ideia de compaixão provinda da nossa organização jurídico-constitucional que transborda para a intervenção penal. A prevenção não é, assim, uma solução perfeita para as influências negativas que se possam lançar sobre a política criminal, mas um caminho que, apesar de se encontrar em construção, não deixa de ser o mais seguro e promissor.

A dimensão emocional do direito penal e políitica criminal preventiva, que vai no sentido da compaixão, apesar de encontrar a sua base nos nossos princípios constitucionais, deverá continuar a ser desenvolvida. Ao perdê-la de vista, podemos ficar desarmados e sem resposta contra o fenómeno do populismo penal.

Despedimo-nos voltando ao mérito da decisão com que abrimos o nosso estudo, trazendo as palavras da Advogada Leonor Caldeira: "Esta decisão tem, obviamente, um relevo de interesse público. Num estado de direito democrático, como sabemos, são os tribunais que decidem as linhas vermelhas da liberdade de expressão e esta sentença confirma que não é possível, a um ator político, humilhar e instrumentalizar pessoas negras, pobres e anónimas como arma retórica e instrumento de campanha política. Isso, para nós, também é muito importante".

53 Sobre isto, Idem, p. 177. 
ULPLR I ULP LAW REVIEW I REVISTA DE DIREITO DA ULP

VOL.15 I №1

DOI: $10.46294 /$ ulplr - rdulp.v15i 1.7938

\section{Bibliografia}

BECCARIA, CESARE, On Crimes and Punishments, Blackmask Online, Ebook, 2001

COSTA, FARIA, O Perigo em Direito Penal, Coimbra: Coimbra Editora, 2000

DA COSTA ANDRADE, MANUEL, "A "Dignidade Penal» e a "Carência de Tutela Penal» como Referências de uma Doutrina Teleológico-Racional do Crime", Revista Portuguesa de Ciência Criminal, Ano 2, Fascículo 2, 1992

DAMÁSIO, ANTÓNIO, O Erro de Descartes: emoção razão e cérebro humano, Temas e debates, 2019

DIAS, FIGUEIREDO, "O «direito penal do bem jurídico» como princípio jurídico-constitucional implícito là luz da jurisprudência constitucional portuguesa)", in: Revista de Legislação e Jurisprudência, Ano 145.. n. 3998, 2016

DIAS, FIGUEIREDO, Direito Penal, Parte Geral, Tomo I- Questões fundamentais; A Doutrina Geral do Crime, Coimbra: Coimbra Editora, 2012

DIAS, FIGUEIREDO, Liberdade, culpa, direito penal, Coimbra: Coimbra Editora, 1995

GOMES CANOTILHO, JOSÉ JOAQUIM, "Justiça Constitucional e Justiça Penal", in: Revista Brasileira de Ciência Criminal, 58, 2006

GRECO, LUÍS, "Tem futuro a teoria do bem jurídico? Reflexões a partir da decisão do Tribunal Constitucional Alemão a respeito do crime de investo (§ 173 Strafgesetzbuch)", in: Revista Brasileira de Ciência Criminal, 82, 2010

JOÃO ANTUNES, MARIA JOÃO, "Perigosidade - Intervenção Estatal em Expansão?", Revista Brasileira de Ciências Criminais, 121,2016

JOÃO ANTUNES, MARIA, Penas e Medidas de Segurança, Coimbra: Almedina, 2018

KINDHAUSER, URS, "Acerca de la concepción de la prevención criminal de Cesare Beccaria", in: Revista Brasileira de Ciências Criminais, Ano 18, n. ${ }^{\circ}$ 87, nov.-dez., 2010

MARQUES DA SILVA, GERMANO, "Populismo e Direito Penal - A Crise Permanente", in: Revista do CEJ, l, 2014

MIRANDA RODRIGUES, ANABELA, "O Modelo de Prevenção na Determinação da Medida Concreta da Pena", in: Revista Portuguesa de Ciência Criminal, Ano 12, n. ${ }^{\circ}$ 2, Abril-Junho, 2002

MIRANDA RODRIGUES, ANABELA, A Determinação da Medida da Pena Privativa de Liberdade: os critérios da culpa e da prevenção, Coimbra: Coimbra Editora, 2014

MIRANDA RODRIGUES, ANABELA, Novo Olhar Sobre a Questão Penitenciária: estatuto jurídico do recluso e socialização jurisdicionalização - consensualismo e prisão - projecto de proposta de lei de execução das penas e medidas privativas de liberdade", Coimbra: Coimbra Editora, 2002

MOURAZ LOPES, JOSÉ, "Fragilidades do discurso criminalizador na corrupção: entre o populismo e a ineficácia", in: Julgar, n. 32,2017 
QUEIROZ , CRISTINA M. M., "A crise da democracia representativa: autoritarismo, demagogia e populismo", in: Estudos em Homenagem ao Conselheiro Presidente Joaquim de Sousa Ribeiro, Volume I, Direito Constitucional, Coimbra: Almedina, 2019 ROSLING, HANS, ROSLING, OLA, RONNLUND, ANNA ROSLING, Factfulness, Sceptre, 2019 